\title{
Effect of Capsosiphon fulvescens on Ethanol-induced Liver Damage in HepG2 Cells over Expressing CYP2E1
}

\author{
Haneul Jo ${ }^{1, \#}$, Ok-Kyung Kim ${ }^{1,2, \#}$, Ho-Geun Yoon ${ }^{3}$, Eungpil Kim ${ }^{4}$, Kyungmi Kim ${ }^{5}$, Yoo-Hyun Lee ${ }^{6}$, \\ Kyung-Chul Choi ${ }^{7}$, Jeongmin Lee ${ }^{8}$, Jeongjin Park ${ }^{1,2, *}$, Woojin Jun ${ }^{1,2, *}$ \\ ${ }^{1}$ Division of Food and Nutrition, Chonnam National University, Gwangju, South Korea \\ ${ }^{2}$ Research Institute for Human Ecology, Chonnam National University, Gwangju, South Korea \\ ${ }^{3}$ Department of Biochemistry and Molecular Biology, Brain Korea 21 PLUS Project for Medical Sciences, \\ Yonsei University College of Medicine, Seoul, South Korea \\ ${ }^{4}$ Marine Biotechnology Research Center, Wando, South Korea \\ ${ }^{5}$ Department of Biofood Analysis, Korea Bio Polytechnic, Ganggyung, South Korea \\ ${ }^{6}$ Department of Food and Nutrition, The University of Suwon, Suwon, South Korea \\ ${ }^{7}$ Department of Biomedical Sciences and Department of Pharmacology, University of Ulsan College of Medicine, Seoul, South Korea \\ ${ }^{8}$ Department of Medical Nutrition, Kyung Hee University, Yongin, South Korea \\ \# Equally contributed to this work. \\ *Corresponding author:pjj8425@hanmail.net; wjjin@chonnam.ac.kr
}

\begin{abstract}
In the present study, the protective effects of $10 \%$ ethanol extract of Capsosiphon fulvescens (CFE10) against alcoholic liver damage were investigated in vitro using CYP2E1-overexpressing hepatocytes (HepG2/2E1). To determine whether CFE10 attenuated ethanol-induced cell death, we compared the viability of HepG2/2E1 cells treated with $250 \mathrm{mM}$ ethanol in the presence or absence of CFE10. Cell viability significantly increased after treatment with CFE10 and ethanol compared with that of cells treated with only ethanol. Additionally, CFE10 inhibited ethanol-induced ROS formation and lipid peroxidation. We also found that CFE10 attenuated the mRNA expression of CYP2E1, as well as decreased ethanol-induced lipid droplets, through stimulation of the AMPK pathway. Based on these results, the protective effect of CFE10 extract from C. fulvescens against liver damage and fatty liver induced by ethanol may occur via the alleviation of oxidative stress.
\end{abstract}

Keywords: capsosiphon fulvescens, alcohol, CYP2E1, reactive oxygen species, liver damage

Cite This Article: Haneul Jo, Ok-Kyung Kim, Ho-Geun Yoon, Eungpil Kim, Kyungmi Kim, Yoo-Hyun Lee, Kyung-Chul Choi, Jeongmin Lee, Jeongjin Park, and Woojin Jun, "Effect of Capsosiphon fulvescens on Ethanol-induced Liver Damage in HepG2 Cells over Expressing CYP2E1." Journal of Food and Nutrition Research, vol. 5, no. 7 (2017): 510-517. doi: 10.12691/jfnr-5-7-9.

\section{Introduction}

Ingested alcohol (ethanol) is absorbed from the stomach and small intestine. As it cannot be stored in the body, it is subsequently oxidized in the liver [1]. In the liver, alcohol is converted to acetaldehyde by alcohol dehydrogenase (ADH), a cytosolic enzyme, or cytochrome P-450 2E1 (CYP2E1), a membrane-bound protein. Acetaldehyde is oxidized to acetate by the mitochondrial enzyme acetaldehyde dehydrogenase (ALDH), which ultimately produces $\mathrm{CO} 2$ and water [2]. The metabolism of alcohol in the liver induces the increase of NADH and reactive oxygen species (ROS), which can cause several liver diseases including alcoholic fatty liver, alcoholic hepatitis, alcoholic fibrosis, and alcoholic cirrhosis [3].

CYP2E1 has been shown to be upregulated by a chronic or excessive alcohol intake and is a major factor in oxidative stress and liver injury via the generation of ROS. Thus, chronic or excessive alcohol consumption can induce the overproduction of ROS, which destroys the antioxidant defense systems and leads to oxidative stress in the liver $[2,3,4]$. Although the body has several antioxidant defense systems for the elimination of ROS, including antioxidant nutrients and enzymes such as superoxide dismutase (SOD), catalase (CAT), glutathione peroxidase (GPx), glutathione reductase (GR), and glutathione (GSH), when ROS levels reach a certain threshold, the antioxidant defense systems are aggravated and subsequently induce lipid peroxidation (LPO) and cell damage in the liver [5].

In the liver, an increase in the redox potential (NADH/NAD) by alcohol oxidation promotes fatty liver and cell damage through inhibition of fatty acid oxidation and the activation of the TCA cycle [6]. In addition, several recent reports have shown that ROS production by CYP2E1 activation caused hepatic lipogenesis through the inhibition of AMP-activated protein kinase (AMPK) expression and an increase in the expression of sterol regulatory element-binding protein (SREBP)-1 [7,8,9]. Because AMPK is necessary for cellular energy homeostasis, including fatty acid oxidation and the inhibition of lipogenesis in the liver, the inhibition of AMPK may be a key factor in the development of fatty liver and liver injury arising from alcohol consumption 
$[6,7,8,9]$. Therefore, alcohol-induced CYP2E1 activation plays a key role in the development of liver damage.

According to the 2014 survey "The State of World Fisheries and Aquaculture", there were approximately 16 million tons of aquatic plants, of which 14.9 million tons were produced by aquaculture [10]. Recent studies have established several components in aquatic plants that are biologically active or show effects on health [11]. In the present study, we assessed the potential hepatoprotective effects of Capsosiphon fulvescens, which is a green algae belonging to the Ulotrichaceae family, traditionally eaten in the southwestern regions of Korea. Although some studies have reported the antioxidant [12], anticancer [13], and immunomodulatory effects [14] of C. fulvescens, the hepatoprotective effects have not been studied. Therefore, we investigated the hepatoprotective effects of $10 \%$ ethanol extract from $C$. fulvescens against ethanol-induced oxidative stress in HepG2 cells overexpressing CYP2E1 (HepG2/2E1).

\section{Methods}

\subsection{Extraction}

C. fulvescens was harvested from Wando (Jeonnam, Korea). Dried, whole C. fulvescens was ground into powder. The powder of $C$. fulvescens $(25 \mathrm{~g})$ was refluxed with $1.5 \mathrm{~L}$ of $10 \%$ ethanol at $250^{\circ} \mathrm{C}$ for $3 \mathrm{~h}$. The extract was filtered with Whatman paper No. 6 and concentrated in rotary evaporator under reduced pressure. The concentrate was lyophilized and stored at $-20^{\circ} \mathrm{C}$ until used. The yield of $10 \%$ ethanol extract of $C$. fulvescens (CFE10) was $25.2 \pm 0.6 \%$.

\subsection{Cell Culture and Transfection}

The HepG2 cell line was obtained from the American Type Culture Collection (Rockville, MD, USA). The vector containing human CYP2E1 cDNA was transfected into the cells by using Lipofectamine $2000^{\mathrm{TM}}$ transfection reagent (Invitrogen, Carlsbad, CA, USA) to produce CYP2E1-overexpressing HepG2 cells (HepG2/2E1). After $24 \mathrm{~h}$, the cells were trypsinized and seeded at a low cell density into $10-\mathrm{cm}$ culture dishes in minimum essential medium (MEM) containing 10\% fetal bovine serum (FBS) with $24 \mu \mathrm{g}$ plasmid DNA. The transfected cells were grown in MEM supplemented with $10 \%$ FBS and $1 \%$ antibiotics $(100 \mathrm{U} / \mathrm{mL}$ penicillin $A$ and $100 \mathrm{U} / \mathrm{mL}$ streptomycin) and were maintained at $37^{\circ} \mathrm{C}$ in a humidified atmosphere of $5 \% \mathrm{CO}_{2}$.

\subsection{Cytotoxicity}

The cells were seeded at $5 \times 10^{4}$ cells/well in a 24 -well culture plate and grown as described above. After incubation for $16 \mathrm{~h}$, the medium was removed and the cultured cells were washed twice with $1 \times$ PBS. Then, 1 $\mathrm{mL}$ MEM containing 3\% FBS with CFE10 was transferred into each well and $250 \mathrm{mM}$ ethanol was added. After incubation for 5 days, a colorimetric cell viability assay was performed. Freshly prepared XTT-PMS solution $(0.25 \mathrm{~mL}$; composed of $1 \mathrm{mg}$ XTT and $10 \mathrm{mg}$ $\mathrm{PMS} / \mathrm{mL}$ phosphate-buffered saline [PBS]) was added to each well and incubated for an additional $2 \mathrm{~h}$. After incubation, the absorbance was measured at a wavelength of $450 \mathrm{~nm}$ by using a spectrophotometer. The cytotoxicity was expressed as a percentage relative to the control wells, which contained no sample.

\subsection{Hepatoprotective Effects}

The cells were seeded at $5 \times 10^{4}$ cells/well in a 24 -well culture plate and grown as described above. After incubation for $16 \mathrm{~h}$, the medium was removed and the cultured cells were washed twice with $1 \times$ PBS. Then, $1 \mathrm{~mL}$ MEM containing 3\% FBS with CFE10 was transferred into each well and $250 \mathrm{mM}$ ethanol was added. After incubation for 5 days, the cytotoxicity was measured according to the XTT assay described above.

\subsection{Measurement of Intracellular ROS}

Intracellular ROS levels were detected using the fluorescence probe 2',7'-dichlorofluorescein diacetate (DCF-DA). The cells were seeded at $5 \times 10^{4}$ cells/well in a 24-well culture plate and grown as described above. After incubation for $16 \mathrm{~h}$, the medium was removed and the cultured cells were washed twice with $1 \times$ PBS. Then, 1 $\mathrm{mL}$ MEM containing 3\% FBS with CFE10 was transferred into each well and $250 \mathrm{mM}$ ethanol was added. After incubation for 5 days, the cells were incubated with $30 \mu \mathrm{M}$ DCF-DA for an additional $30 \mathrm{~min}$ at $37^{\circ} \mathrm{C}$. The fluorescence intensity in the cells was measured on a plate fluorescence reader with an excitation wavelength of 485 $\mathrm{nm}$ and an emission wavelength of $530 \mathrm{~nm}$.

\subsection{Measurement of Antioxidant Enzyme Activity}

The cells were grown in a 100-mm culture dish. At $16 \mathrm{~h}$ after seeding, the growth medium was removed and the cells were washed twice with PBS. Then, $1 \mathrm{~mL}$ MEM containing 3\% FBS with CFE10 was transferred into each well and $250 \mathrm{mM}$ ethanol was added. After incubation for 5 days, the cells were harvested and lysed using CelLytic $^{\mathrm{TM}}$ MT cell lysis reagent. SOD activity was assayed by the method of McCord and Fridovich (1969) [15], CAT activity was determined as described by Aebi (1984) [16], hepatic glutathione-S-transferase (GST) activity was assayed according to the method of Habig and Jakoby (1981) [17], GPx activity was estimated by the method of Pagila and Valentine (1967) [18], and GR activity was measured using an adaptation of the method of Calberg and Mannervik (1975) [19]. The level of glutathione (GSH), a key intracellular antioxidant, was measured by method of Akerboom and Sies (1981) [20].

The concentration of malondialdehyde (MDA), the end product of lipid peroxidation, was assayed by monitoring thiobarbituric acid reactive substance formation as described by Draper and Hadley (1990) [21]. The amount of protein was estimated using the Bradford assay. 


\subsection{Measurement of Intracellular Lipid Droplets}

The cells were seeded at $5 \times 10^{4}$ cells/well in a 24-well plate. At $16 \mathrm{~h}$ after seeding, the growth medium was removed and washed twice with PBS. Then, $1 \mathrm{~mL}$ MEM containing 3\% FBS with CFE10 was transferred into each well and $250 \mathrm{mM}$ ethanol was added. After incubation for 5 days, the cells were harvested and the level of intracellular lipid droplets was measured using AdipoRed ${ }^{\mathrm{TM}}$ Assay Reagent kits (Lonza, Walkersville, MD, USA).

\subsection{Isolation of Total RNA and Real-time PCR}

Total RNA was extracted using the easy-BLUE ${ }^{\mathrm{TM}}$ total RNA extraction kit (Intron Biotechnology, Gyeonggi-do, Korea) and complementary DNA was synthesized from purified total RNA in the reaction buffer by using the iScript $^{\mathrm{TM}}$ cDNA Synthesis Kit (Bio-Rad Laboratories, Hercules, CA, USA). Real-time PCR was performed using a SYBR green RT-PCR kit obtained from Qiagen (Venlo, Netherlands) and custom-designed primers (Table 1). The cDNA was amplified for 40 cycles of denaturation $\left(95^{\circ} \mathrm{C}\right.$ for $30 \mathrm{~s})$, annealing $\left(58^{\circ} \mathrm{C}\right.$ for $\left.30 \mathrm{~s}\right)$, and extension $\left(72^{\circ} \mathrm{C}\right.$ for $45 \mathrm{~s})$. The results of the real-time RT-PCR were processed with the 7500 System SDS software version 1.3.1 (Applied Biosystems, Foster City, CA, USA), which was also used to process the quantitative data.

\subsection{Statistical Analysis}

Data are presented as the mean $\pm \mathrm{SD}$. The data were statistically evaluated with one-way ANOVA using SPSS statistical procedures for Windows (SPSS PASW Statistics 22.0, SPSS Inc. Chicago, IL, USA) and Duncan's multiple range test was used to compare significant differences between the groups at $p<0.05$.

\section{Results}

\subsection{Cytotoxicity and Hepatoprotective Effects of $C$. fulvescens Extract in HepG2/2E1 Cells Treated with Ethanol}

CFE10 showed no signs of cytotoxicity at 200-1000 $\mu \mathrm{g} / \mathrm{mL}$ in HepG2/2E1 cells (Figure 1). We investigated the effect of $200 \mu \mathrm{g} / \mathrm{mL}$ and $500 \mu \mathrm{g} / \mathrm{mL}$ CFE10 in ethanol-treated HepG2/2E1 cells.

Table 1. Primer sets used for real-time PCR

\begin{tabular}{|c|c|c|}
\hline Gene & & Sequence \\
\hline \multirow{2}{*}{$\beta$-Actin } & $\mathrm{F}$ & 5'- ACGGCCAGGTCATCACTATTG-3' \\
\hline & $\mathrm{R}$ & 5'- CAAGAAGGAAGGCTGGAAAAGA-3' \\
\hline \multirow{2}{*}{ CYP2E1 } & $\mathrm{F}$ & 5'- CGTGGAAATGGAGAAGGAAA-3' \\
\hline & $\mathrm{R}$ & 5'- GGTGATGAACCGCTGAATCT-3' \\
\hline \multirow{2}{*}{ AMPK } & $\mathrm{F}$ & 5'- GGCACCCTCCCATTTGATG-3' \\
\hline & $\mathrm{R}$ & 5'- ACACCCCCTCGGATCTTCTT-3' \\
\hline SREBP-1c & $\mathrm{R}$ & 5'- GCCGGTTGATAGGCAGCTT-3' \\
\hline \multirow{2}{*}{$\mathrm{ACC}$} & $\mathrm{F}$ & 5'- TGCAGATCTTAGCGGACCAA-3' \\
\hline & $\mathrm{R}$ & 5'- GCCTGCGTTGTACAGAGCAA-3' \\
\hline \multirow{2}{*}{ CPT-1 } & $\mathrm{F}$ & 5'- TGTTGGGTATGCTGTTCATGACA-3' \\
\hline & $\mathrm{R}$ & 5'- GCGGCCTGGGTAGGAAGA-3' \\
\hline PPAR- $\alpha$ & $\mathrm{F}$ & 5'- AACATCCAAGAGATTTCGCAATC-3' \\
\hline
\end{tabular}

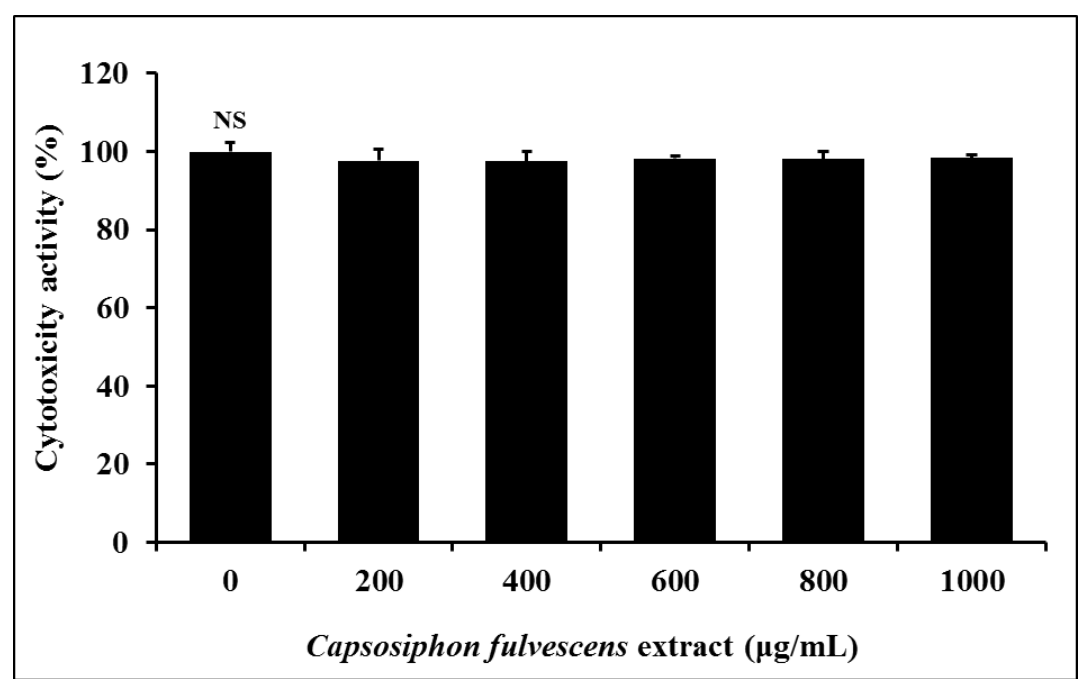

Figure 1. Viability of the HepG2/2E1 cells following treatment for 5 days with different concentrations of $10 \%$ ethanol extract of Capsosiphon fulvescens (CFE10). The data are expressed as the mean $\pm \mathrm{SD}(\mathrm{n}=3)$ and significant differences were analyzed using Duncan's multiple-range test. $\mathrm{NS}=$ not significant. 


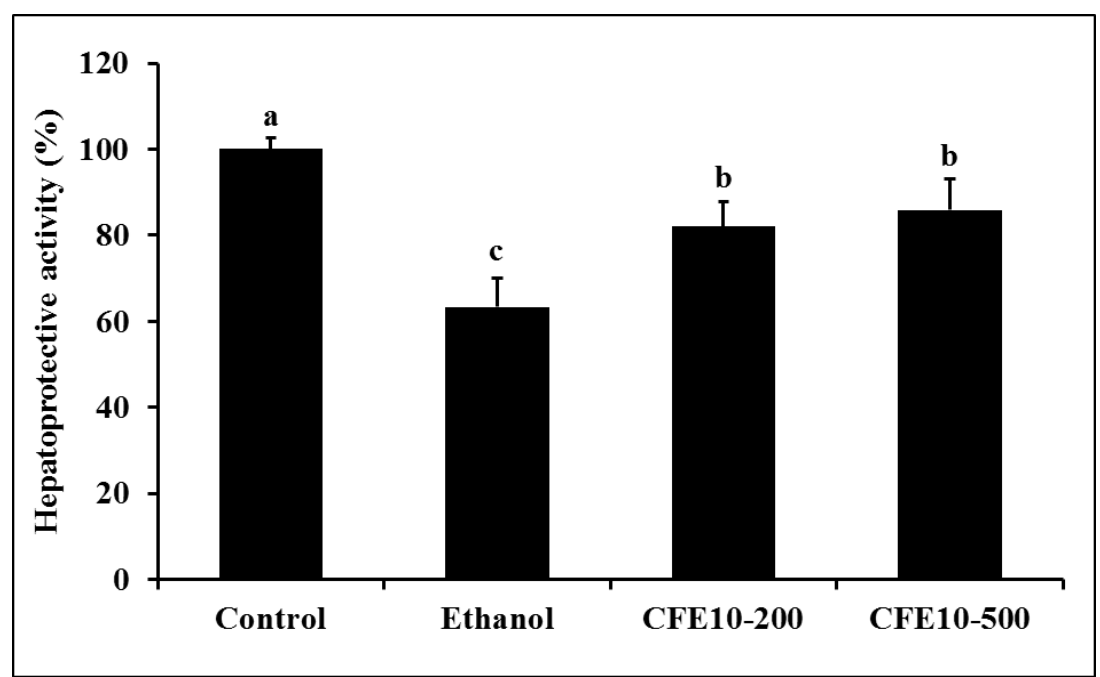

Figure 2. Hepatoprotective effects of $10 \%$ ethanol extract of Capsosiphon fulvescens (CFE10) in ethanol-treated HepG2/2E1 cells. The data are expressed as the mean $\pm \mathrm{SD}(\mathrm{n}=3)$, and different letters indicate $(\mathrm{a}>\mathrm{b}>\mathrm{c})$ a significant difference at $p<0.05$, as determined by a Duncan's multiple range test

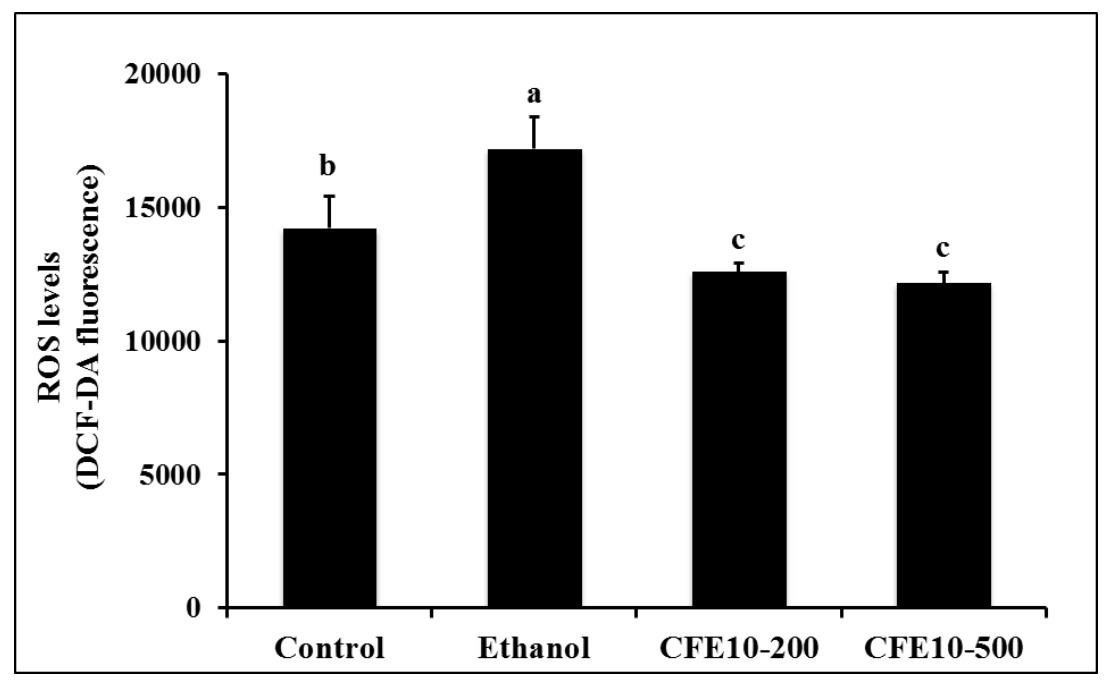

Figure 3. Effects of $10 \%$ ethanol extract of Capsosiphon fulvescens (CFE10) on the production of intracellular ROS in ethanol-treated HepG2/2E1 cells. The data are expressed as the mean $\pm \mathrm{SD}(\mathrm{n}=3)$, and different letters indicate $(\mathrm{a}>\mathrm{b}>\mathrm{c})$ a significant difference at $p<0.05$, as determined by a Duncan's multiple range test

Table 2. Effects of Capsosiphon fulvescens extracted by $10 \%$ ethanol (CFE10) on antioxidant enzyme activity in ethanol-treated HepG2/2E1 cells

\begin{tabular}{ccccccc}
\hline & $\begin{array}{c}\text { CAT } \\
\mathrm{mU} / \mathrm{mg} \text { protein }\end{array}$ & $\begin{array}{c}\text { SOD } \\
\mathrm{mU} / \mathrm{mg} \text { protein }\end{array}$ & $\begin{array}{c}\text { GST } \\
\mathrm{mU} / \mathrm{mg} \text { protein }\end{array}$ & $\begin{array}{c}\text { GR } \\
\mathrm{mU} / \mathrm{mg} \text { protein }\end{array}$ & $\begin{array}{c}\text { GPx } \\
\mathrm{mU} / \mathrm{mg} \text { protein }\end{array}$ & $\begin{array}{c}\text { GSH } \\
\mathrm{mU} / \mathrm{mg} \text { protein }\end{array}$ \\
\hline Control & $1692.24 \pm 41.64^{\mathrm{a}}$ & $76.95 \pm 9.61^{\mathrm{a}}$ & $12.67 \pm 2.04^{\mathrm{a}}$ & $127.55 \pm 8.18^{\mathrm{a}}$ & $21.90 \pm 1.78^{\mathrm{a}}$ & $27.16 \pm 1.31^{\mathrm{a}}$ \\
Ethanol & $875.70 \pm 146.46^{\mathrm{c}}$ & $59.65 \pm 5.09^{\mathrm{b}}$ & $8.38 \pm 1.95^{\mathrm{b}}$ & $91.40 \pm 8.47^{\mathrm{b}}$ & $16.34 \pm 1.20^{\mathrm{b}}$ & $16.61 \pm 1.16^{\mathrm{b}}$ \\
CFE10-200 & $1258.32 \pm 146.32^{\mathrm{b}}$ & $72.06 \pm 9.93^{\mathrm{a}}$ & $11.52 \pm 0.95^{\mathrm{a}}$ & $122.03 \pm 4.40^{\mathrm{a}}$ & $20.24 \pm 3.45^{\mathrm{a}}$ & $25.46 \pm 1.53^{\mathrm{a}}$ \\
CFE10-500 & $1356.09 \pm 136.55^{\mathrm{b}}$ & $74.06 \pm 4.24^{\mathrm{a}}$ & $12.63 \pm 1.97^{\mathrm{a}}$ & $125.48 \pm 2.85^{\mathrm{a}}$ & $21.39 \pm 1.89^{\mathrm{a}}$ & $26.20 \pm 1.69^{\mathrm{a}}$ \\
\hline
\end{tabular}

The data are expressed as the mean $\pm \mathrm{SD}(\mathrm{n}=3)$, and different letters indicate $(\mathrm{a}>\mathrm{b}>\mathrm{c})$ a significant difference at $p<0.05$, as determined by a Duncan's multiple range test.

The protective effects of $200 \mu \mathrm{g} / \mathrm{mL}$ and $500 \mu \mathrm{g} / \mathrm{mL}$ CFE10 against ethanol-induced toxicity are illustrated in Figure 2. The viability of ethanol-treated HepG2/2E1 cells significantly decreased $(63.38 \pm 6.71 \%)$ compared with that of the control cells. When the ethanol-treated HepG2/2E1 cells were treated with $200 \mu \mathrm{g} / \mathrm{mL}$ and 500 $\mu \mathrm{g} / \mathrm{mL}$ CFE 10 , viability significantly increased to $81.98 \pm$ $5.91 \%$ and $85.81 \pm 7.14 \%$, respectively, compared with that of ethanol-induced HepG2/2E1 cells $(p<0.05)$.

\subsection{Effects of $C$. fulvescens Extract on the Production of Intracellular ROS}

In ethanol-treated HepG2/2E1 cells, the level of intracellular ROS $(17167.0 \pm 1206.10)$ significantly increased when compared with that in the normal control group $(14203.5 \pm 1209.35)$. A significant decrease in the level of intracellular ROS was observed in the cells treated with $200 \mu \mathrm{g} / \mathrm{mL}$ CFE10 $(12586.3 \pm 318.27)$ and 500 
$\mu \mathrm{g} / \mathrm{mL}$ CFE10 (12142.3 \pm 434.69$)$ compared with that in ethanol-induced HepG2/2E1 cells $(p<0.05)$ (Figure 3).

\subsection{Effects of $C$. fulvescens Extract on Antioxidant Enzyme Activity}

Compared with the normal control group, the ethanolinduced HepG2/2E1 cells showed significant decreases in the activities of CAT, SOD, GST, GR, GPx, and GSH. When the ethanol-induced HepG2/2E1 cells were treated with $200 \mu \mathrm{g} / \mathrm{mL}$ and $500 \mu \mathrm{g} / \mathrm{mL}$ CFE10, the activities of CAT, SOD, GST, GR, GPx, and GSH significantly increased compared with that in ethanol-treated HepG2/2E1 cells $(p<0.05)$ (Table 2$)$.

\subsection{Effects of $C$. fulvescens Extract on Lipid Peroxidation}

We measured the levels of malondialdehyde (MDA), which is the end product of lipid peroxidation. The level of MDA was significantly increased in the ethanol-induced HepG2/2E1 cells compared with the normal control group. However, treatment with 200 $\mu \mathrm{g} / \mathrm{mL}$ and $500 \mu \mathrm{g} / \mathrm{mL}$ CFE10 resulted in a significant decrease in the level of MDA compared with the ethanoltreated HepG2/2E1 cells $(p<0.05)$ (Figure 4).

\subsection{Effects of $C$. fulvescens Extract on the Production of Intracellular Lipid Droplets}

We found that the production of intracellular lipid droplets markedly increased in ethanol-treated HepG2/2E1 cells compared with that in the normal control group. The groups that were also treated with CFE10 showed significant decreases in the production of intracellular lipid droplets compared with that in the ethanol-treated HepG2/2E1 cells $(p<0.05)$ (Figure 5).

\subsection{Effects of $C$. fulvescens Extract on mRNA Expression}

The ethanol-treated HepG2/2E1 cells showed a significant increase in the mRNA expression of CYP2E1 compared with that in the normal control group. Treatment with $200 \mu \mathrm{g} / \mathrm{mL}$ and $500 \mu \mathrm{g} / \mathrm{mL}$ CFE10 showed a significant decrease in the mRNA expression of CYP2E1 compared with that in the ethanol-induced HepG2/2E1 cells $(p<0.05)$ (Figure 6).

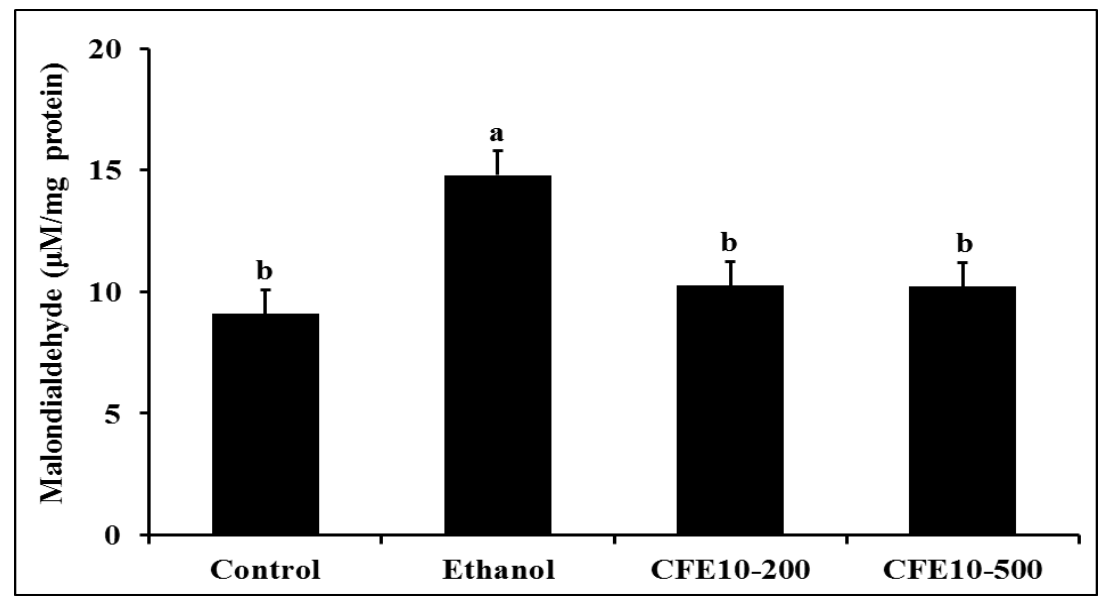

Figure 4. Effects of $10 \%$ ethanol extract of Capsosiphon fulvescens (CFE10) on lipid peroxidation (production of malondialdehyde) in ethanol-treated HepG2/2E1 cells. The data are expressed as the mean $\pm \mathrm{SD}(\mathrm{n}=3)$, and different letters indicate (a $>\mathrm{b})$ a significant difference at $p<0.05$, as determined by a Duncan's multiple range test

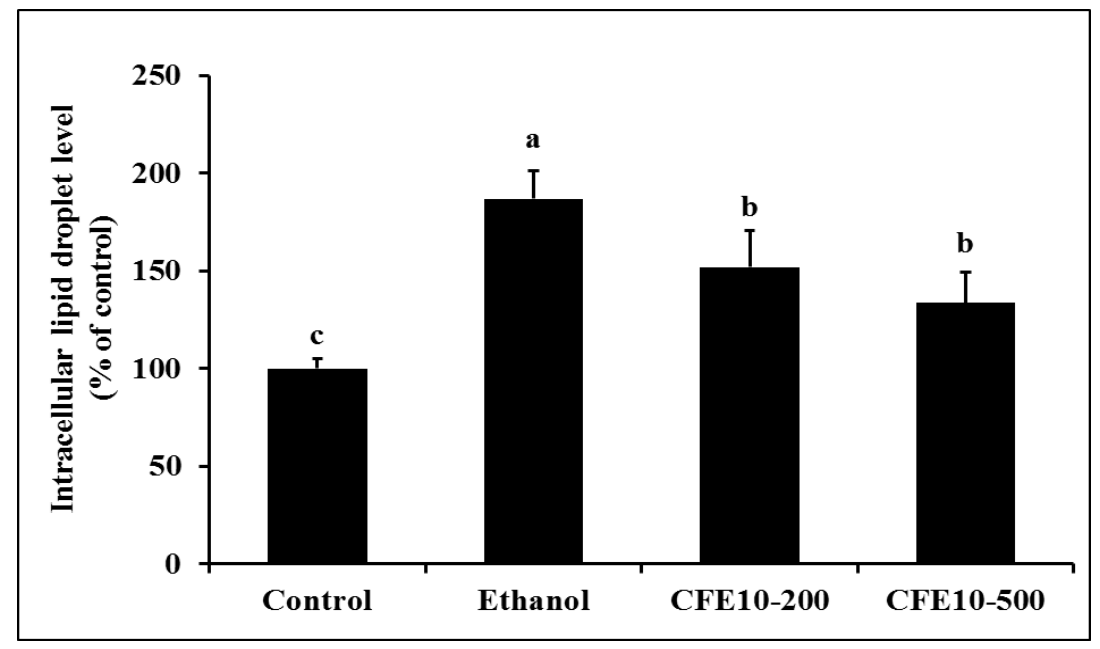

Figure 5. Effects of $10 \%$ ethanol extract of Capsosiphon fulvescens (CFE10) on the production of intracellular lipid droplets in the ethanol-treated HepG2/2E1 cells. The data are expressed as the mean $\pm \mathrm{SD}(\mathrm{n}=3)$, and different letters indicate $(\mathrm{a}>\mathrm{b}>\mathrm{c})$ a significant difference at $p<0.05$, as determined by a Duncan's multiple range test 


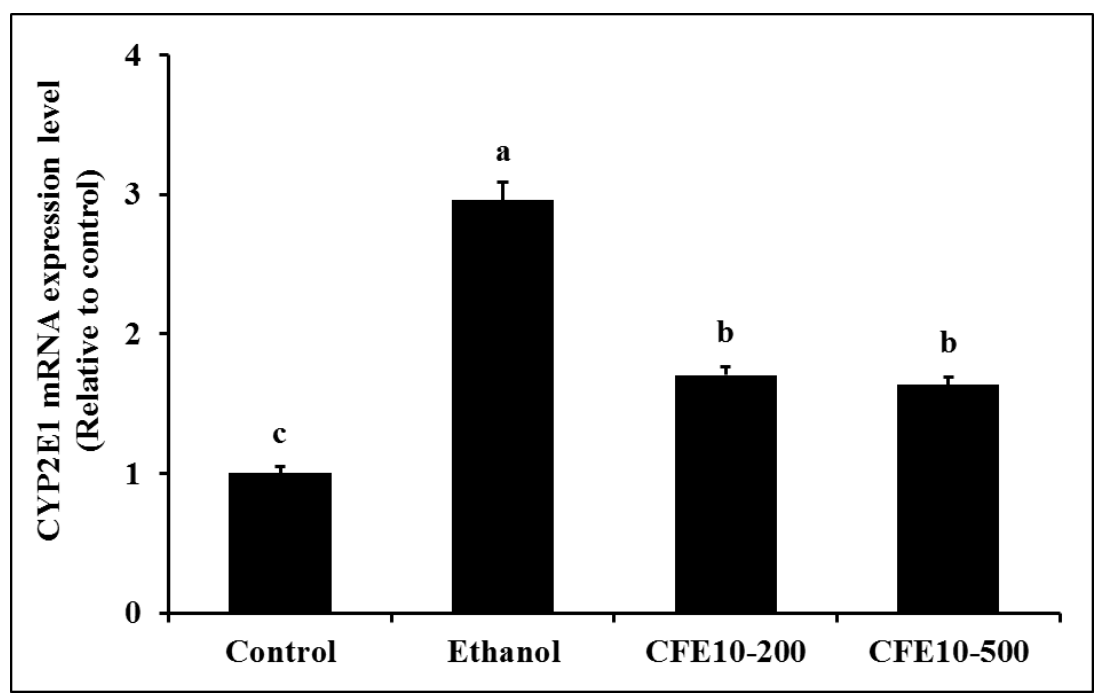

Figure 6. Effects of 10\% ethanol extract of Capsosiphon fulvescens (CFE10) on the mRNA expression of CYP2E1 in ethanol-treated HepG2/2E1 cells. The data are expressed as the mean $\pm \mathrm{SD}(\mathrm{n}=3)$, and different letters indicate $(\mathrm{a}>\mathrm{b}>\mathrm{c})$ a significant difference at $p<0.05$, as determined by a Duncan's multiple range test

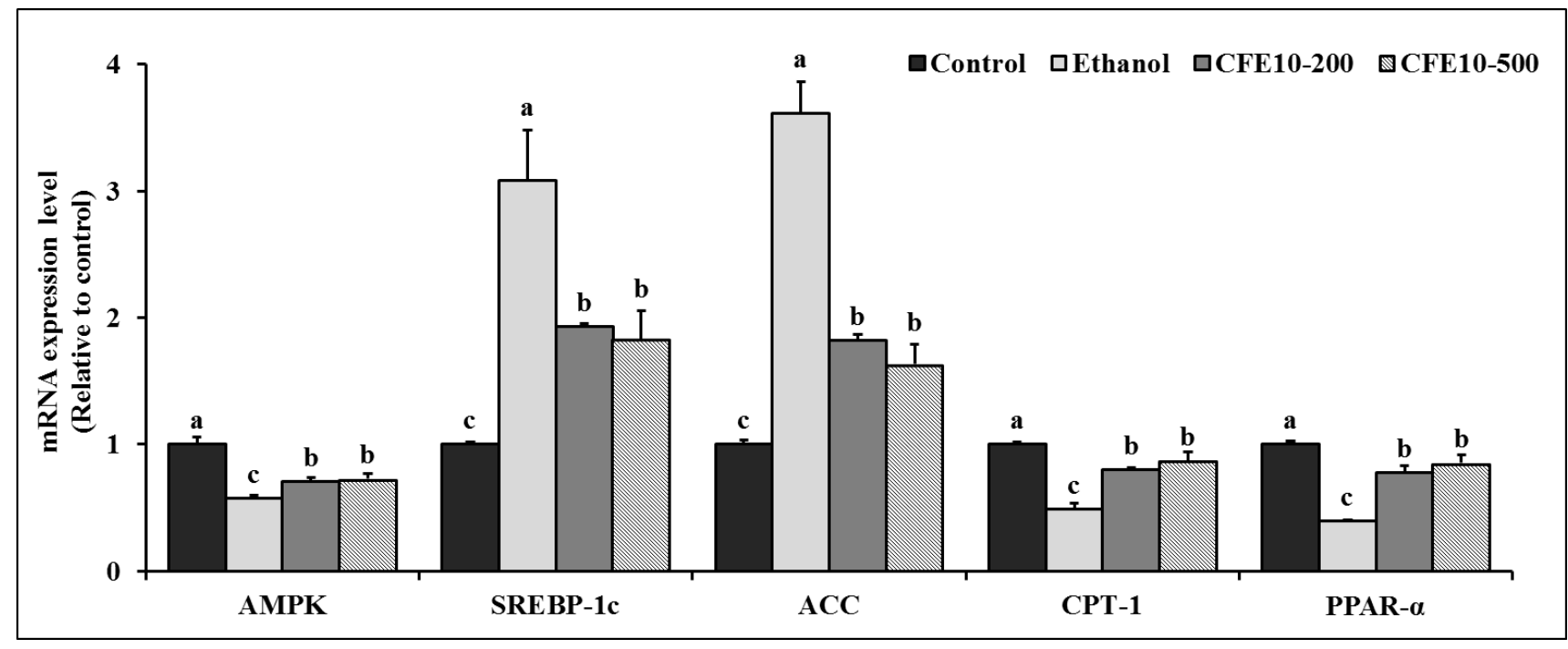

Figure 7. Effects of $10 \%$ ethanol extract of Capsosiphon fulvescens (CFE10) on the mRNA expression of AMPK, SREBP-1c, ACC, CPT-1, and PPAR$\alpha$ in ethanol-treated HepG2/2E1 cells. The data are expressed as the mean $\pm \mathrm{SD}(\mathrm{n}=3)$, and different letters indicate $(\mathrm{a}>\mathrm{b}>\mathrm{c})$ a significant difference at $p<0.05$, as determined by a Duncan's multiple range test

In addition, significant increases in the mRNA expression of SREBP-1c and ACC and decreases in the mRNA expression of AMPK, CPT1, and PPAR- $\alpha$ were observed in the ethanol-treated HepG2/2E1 cells compared with that in the normal control group. However, the ethanol-treated HepG2/2E1 cells that were also treated with $200 \mu \mathrm{g} / \mathrm{mL}$ and $500 \mu \mathrm{g} / \mathrm{mL}$ CFE10 showed a significant decrease in the mRNA expression of SREBP-1c and ACC and increases in the mRNA expression of AMPK, CPT1, and PPAR- $\alpha$, compared with the levels of the ethanol-treated HepG2/2E1 cells $(p<0.05)$ (Figure 7).

\section{Discussion}

The liver participates in approximately 500 different functions; one of the most important of these is energy metabolism. In the liver, fatty acids, triacylglycerols, and cholesterol are exported as fatty packages, such as very low-density lipoprotein (VLDL), and delivered to the body via the blood. However, lipids cannot be stored in liver cells [22]. The accumulation of excess lipid droplets in liver cells is called fatty liver (steatosis). Fatty liver is vulnerable to further inflammation, termed steatohepatitis, which may cause liver damage. As liver cells do not normally export or break down fats, the consumption of excess calories causes fatty liver [23]. In addition, the most common cause of fatty liver is excessive alcohol consumption, which induces alcoholic liver diseases such as alcoholic hepatitis and cirrhosis [3,23]. In the liver, the primary enzymes involved in alcohol metabolism are $\mathrm{ADH}, \mathrm{CYP} 2 \mathrm{E} 1$, and catalase. Several reports have shown that chronic or excessive alcohol consumption increased the activation of CYP2E1 in the oxidative pathways of alcohol metabolism, which may contribute to the pathogenesis of alcoholic liver damage through ROS production during the catalytic circle $[2,24]$. In this study, we used HepG2 cells transfected with human CYP2E1 to generate an ethanol-induced in vitro model of liver damage.

We found that ethanol induced oxidative stress in HepG2/2E1 cells through the increase of ROS production 
and lipid peroxidation during a decrease in the activity of antioxidant enzymes. $\mathrm{Lu}$ et al. reported that CYP2E1 played a role in ethanol-induced oxidative stress and the depletion of antioxidant enzymes caused alcoholic liver injury in an in vivo assay. The ethanol-induced increase in CYP2E1 caused oxidative stress and lipid peroxidation, which led to cell damage through lipid oxidation in the cell membrane [2]. Therefore, antioxidant supplements may suppress alcohol-induced liver damage.

We investigated the hepatoprotective effects of CFE10 against ethanol-induced oxidative stress in HepG2/2E1 cells. CFE10 treatment in ethanol-treated HepG2/2E1 cells caused a significant decrease in ROS production and lipid peroxidation and a significant increase of antioxidant enzyme activity compared with ethanol-treated HepG2/2E1 cells. In addition, treatment with CFE10 significantly increased the viability compared with ethanol-treated HepG2/2E1 cells. A report by Cho et al. found extracts of C. fulvescens showed a strong reducing ability in 2,2-diphenyl-1-picrylhydrazyl and hydroxyl radical assays, which suggested that $C$. fulvescens could be a natural antioxidant [25]. According to this report and our present data, we suggest that CFE10 can suppress ethanol-induced liver cell death by the inhibition of oxidative stress.

CYP2E1-induced oxidative stress can also cause the downregulation of AMPK, which inhibits fatty acid oxidation, but stimulate fatty acid synthesis. It has been reported that the upregulation of AMPK caused an increase in carnitine palmitoyltransferase 1 (CPT1) expression through the PPAR- $\alpha$ pathway and inhibition of acetyl-CoA carboxylase (ACC) through the downregulation of SREBP-1. Thus, ethanol-induced AMPK inhibition in hepatocytes caused the stimulation of ACC and the inhibition of CPT1, which promoted lipid accumulation [26-28]. In this study, we also found that the ethanol treatment of HepG2/2E1 cells caused a significant increase in the mRNA expression of SREBP-1c and ACC and decrease in the mRNA expression of AMPK, CPT1, and PPAR- $\alpha$ compared with the normal control group. However, the treatment of CFE10 suppressed the mRNA expression of SREBP-1c and ACC and increased the mRNA expression of AMPK, CPT1, and PPAR- $\alpha$ in ethanol-treated HepG2/2E1 cells. CFE10 treatment also decreased the production of intracellular lipid droplets induced by ethanol treatment. These results indicated that CFE10 treatment prevented the development of alcoholic liver damage and fatty liver through the stimulation of AMPK.

A study by Rodeiro et al. investigated the chemical composition and biological properties of Ulva fasciata, a marine green algae. The authors showed that $U$. fasciata extract inhibited benzo[a]pyrene-induced cytotoxicity in hepatic C9 cells and also inhibited CYP1A1 activity in rat liver microsomes [29]. Thus, they suggested that marine green algae were a potential source of preventive agents against cancer and other degenerative diseases. In line with this study, our data indicated that green algae may have a preventive effect on liver damage, even though we have not yet revealed the exact mechanism. Our future research will investigate the efficacy mechanism and preventive effect of $C$. fulvescens in an animal model of alcoholic-induced liver damage.

\section{Conclusion}

In summary, we found that $C$. fulvescens exerted a protective effect against alcohol-induced liver damage, which might be strongly associated with the amelioration of oxidative stress. In addition, $C$. fulvescens inhibited lipogenesis via the stimulation of AMPK, PPAR- $\alpha$, and CPT1 and the suppression of SREBP-1 and ACC (Figure 8). Therefore, the development of dietary supplements incorporating $C$. fulvescens may offer protection against alcoholic liver damage and fatty liver mediated by oxidative stress.

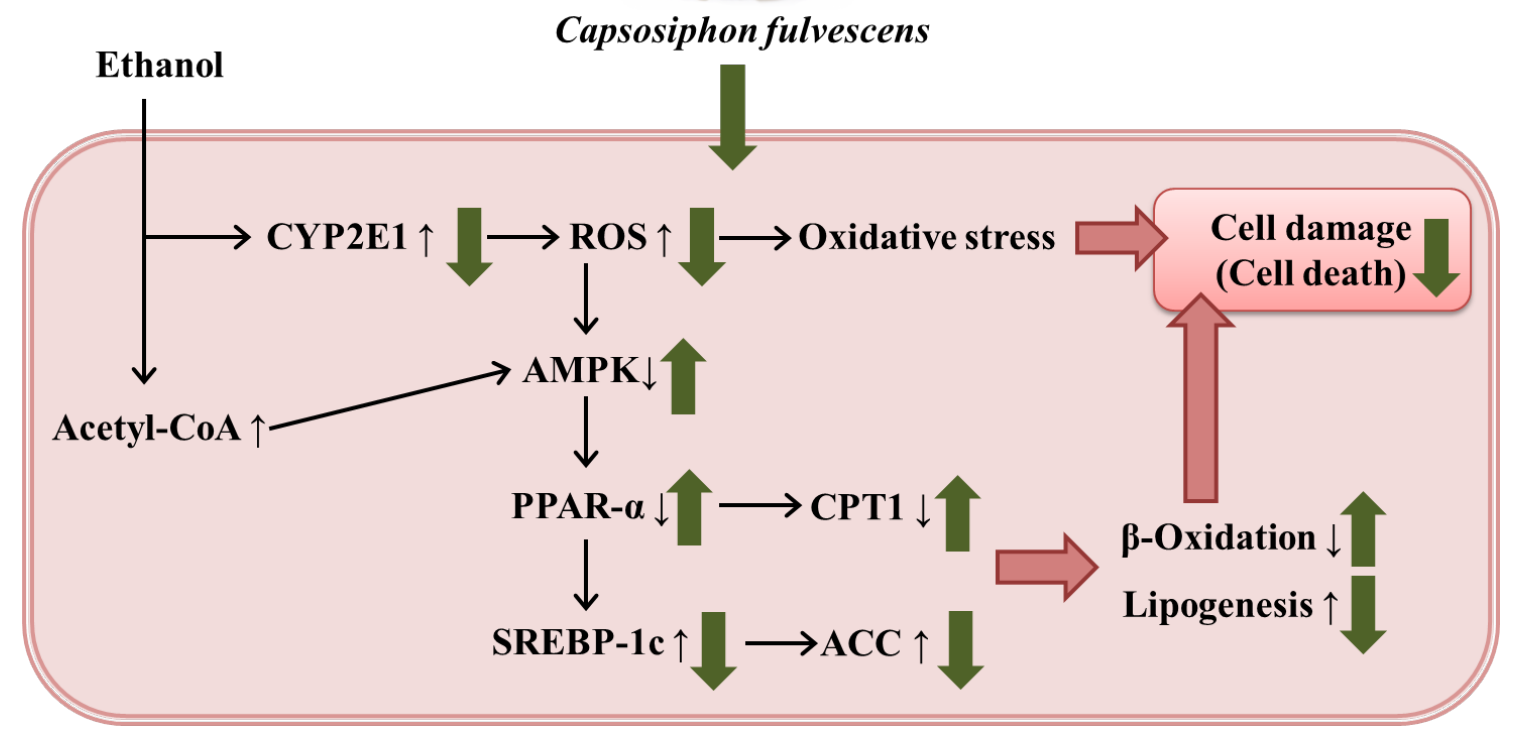

Figure 8. Possible mechanisms of ethanol-induced development of fatty liver via ROS overproduction and effects of $10 \%$ ethanol extract of Capsosiphon fulvescens (CFE10) in ethanol-treated HepG2/2E1 cells 


\section{Acknowledgements}

This research was supported by a grant from the Marine Biotechnology Program (PJT200672) funded by the Ministry of Oceans and Fisheries, Korea.

\section{Conflicts of Interest}

The authors have no conflicts of interest to declare.

\section{References}

[1] Wu, D.; Zhai, Q.; Shi, X. Alcohol-induced oxidative stress and cell responses. J. Gastroenterol. Hepatol. 2006, 21, S26-29.

[2] Lu, Y.; Cederbaum, A.I. CYP2E1 and oxidative liver injury by alcohol. Free Radic. Biol. Med. 2008, 44, 723-738.

[3] Radosavljević, T.; Mladenović, D.; Vucević, D. The role of oxidative stress in alcoholic liver injury. Med. Pregl. 2009, 62, 547-553.

[4] Pérez, M.J.; Cederbaum, A.I. Adenovirus-mediated expression of $\mathrm{Cu} / \mathrm{Zn}$ - or Mn-superoxide dismutase protects against CYP2E1dependent toxicity. Hepatology 2003, 38, 1146-1145.

[5] Koch, O.R.; Pani, G.; Borrello, S.; Colavitti, R.; Cravero, A.; Farrè, S.; Galeotti, T. Oxidative stress and antioxidant defenses in ethanol-induced cell injury. Mol. Aspects Med. 2004, 25, 191-198.

[6] Mantena, S.K.; King, A.L.; Andringa, K.K.; Eccleston, H.B.; Bailey, S.M. Mitochondrial dysfunction and oxidative stress in the pathogenesis of alcohol- and obesity-induced fatty liver diseases. Free Radic. Biol. Med. 2008, 44, 1259-1272.

[7] Emerling, B.M.; Weinberg, F.; Snyder, C.; Burgess, Z.; Mutlu, G.M.; Viollet, B.; Budinger, G.R.; Chandel, N.S. Hypoxic activation of AMPK is dependent on mitochondrial ROS but independent of an increase in AMP/ATP ratio. Free Radic. Biol. Med. 2009, 46, 1386-1391.

[8] Mungai, P.T.; Waypa, G.B.; Jairaman, A.; Prakriya, M.; Dokic, D.; Ball, M.K.; Schumacker, P.T. Hypoxia triggers AMPK activation through reactive oxygen species-mediated activation of calcium release-activated calcium channels. Mol. Cell Biol. 2011, 31, 3531-3545.

[9] Fernández-Alvarez, A.; Alvarez, M.S.; Gonzalez, R.; Cucarella, C.; Muntané, J.; Casado, M. Human SREBP1c expression in liver is directly regulated by peroxisome proliferator-activated receptor alpha (PPARalpha). J. Biol. Chem. 2011, 286, 21466-2177.

[10] The State of World Fisheries and Aquaculture. Food and Agriculture Organization 2014.

[11] Brain, R.A.; Hanson, M.L.; Solomon, K.R.; Brooks, B.W. Aquatic plants exposed to pharmaceuticals: effects and risks. Rev. Environ. Contam. Toxicol. 2008, 192, 67-115.

[12] Kim, E.Y.; Choi, Y.H.; Lee, J.I.; Kim, I.H.; Nam, T.J. Antioxidant Activity of Oxygen Evolving Enhancer Protein 1 Purified from Capsosiphon fulvescens. J. Food Sci. 2015, 80, 1412-1417.

[13] Kwon, M.J.; Nam, T.J. A polysaccharide of the marine alga Capsosiphon fulvescens induces apoptosis in AGS gastric cancer cells via an IGF-IR-mediated PI3K/Akt pathway. Cell Biol. Int. 2007, 31, 768-775.

[14] Karnjanapratum, S.; Tabarsa, M.; Cho, M.; You, S Characterization and immunomodulatory activities of sulfated polysaccharides from Capsosiphon fulvescens. Int. J. Biol. Macromol. 2012, 51, 720-729.

[15] McCord, J.M.; Fridovich, I. Superoxide dismutase. An enzymic function for erythrocuprein (hemocuprein). J. Biol. Chem. 1969, 244, 6049-6055.

[16] Aebi, H. Catalase in vitro. Methods Enzymol. 1984, 105, 121-126.

[17] Habig, W.H.; Jakoby, W.B. Glutathione S-transferases (rat and human). Methods Enzymol. 1981, 77, 218-231.

[18] Paglia, D.E.; Valentine, W.N. Studies on the quantitative and qualitative characterization of erythrocyte glutathione peroxidase. J. Lab. Clin. Med. 1967, 70, 158-169.

[19] Carlberg, I.; Mannervik, B. Purification and characterization of the flavoenzyme glutathione reductase from rat liver. J. Biol. Chem. $1975,250,5475-5480$.

[20] Akerboom, T.P.; Sies, H. Assay of glutathione, glutathione disulfide, and glutathione mixed disulfides in biological samples. Methods Enzymol. 1981, 77, 373-382.

[21] Draper, H.H.; Hadley, M. Malondialdehyde determination as index of lipid peroxidation. Methods Enzymol. 1990, 186, 421-431.

[22] Nguyen, P.; Leray, V.; Diez, M.; Serisier, S.; Le Bloc'h, J.; Siliart, B.; Dumon, H. Liver lipid metabolism. J. Anim. Physiol. Anim. Nutr. 2008, 92, 272-283.

[23] Lieber, C.S. Alcoholic fatty liver: its pathogenesis and mechanism of progression to inflammation and fibrosis. Alcohol 2004, 34, 9-19.

[24] Kessova, I.; Cederbaum, A.I. CYP2E1: biochemistry, toxicology, regulation and function in ethanol-induced liver injury. Curr. Mol. Med. 2003, 3, 509-518.

[25] Cho, M.; Kang, I.J.; Won, M.H.; Lee, H.S.; You, S. The antioxidant properties of ethanol extracts and their solventpartitioned fractions from various green seaweeds. J. Med. Food 2010, 13, 1232-1239.

[26] Sozio, M.S.; Lu, C.; Zeng, Y.; Liangpunsakul, S.; Crabb, D.W. Activated AMPK inhibits PPAR-\{alpha\} and PPAR-\{gamma transcriptional activity in hepatoma cells. Am. J. Physiol. Gastrointest. Liver Physiol. 2011, 301, G739-747.

[27] Nakajima, T.; Kamijo, Y.; Tanaka, N.; Sugiyama, E.; Tanaka, E.; Kiyosawa, K.; Fukushima, Y.; Peters, J.M.; Gonzalez, F.J.; Aoyama, T. Peroxisome proliferator-activated receptor alpha protects against alcohol-induced liver damage. Hepatology 2004, 40, 972-980.

[28] Tang, C.C.; Lin, W.L.; Lee, Y.J.; Tang, Y.C.; Wang, C.J. Polyphenol-rich extract of Nelumbo nucifera leaves inhibits alcohol-induced steatohepatitis via reducing hepatic lipid accumulation and anti-inflammation in $\mathrm{C} 57 \mathrm{BL} / 6 \mathrm{~J}$ mice. Food Funct. 2014, 5, 678-687.

[29] Rodeiro, I.; Olguín, S.; Santes, R.; Herrera, J.A.; Pérez, C.L.; Mangas, R.; Hernández, Y.; Fernández, G.; Hernández, I.; Hernández-Ojeda, S.; Camacho-Carranza, R.; Valencia-Olvera, A.; Espinosa-Aguirre, J.J. Gas Chromatography-Mass Spectrometry Analysis of Ulva fasciata (Green Seaweed) Extract and Evaluation of Its Cytoprotective and Antigenotoxic Effects. Evid. Based Complement Alternat. Med. 2015, 520598. 